AUFZEICHNEN 


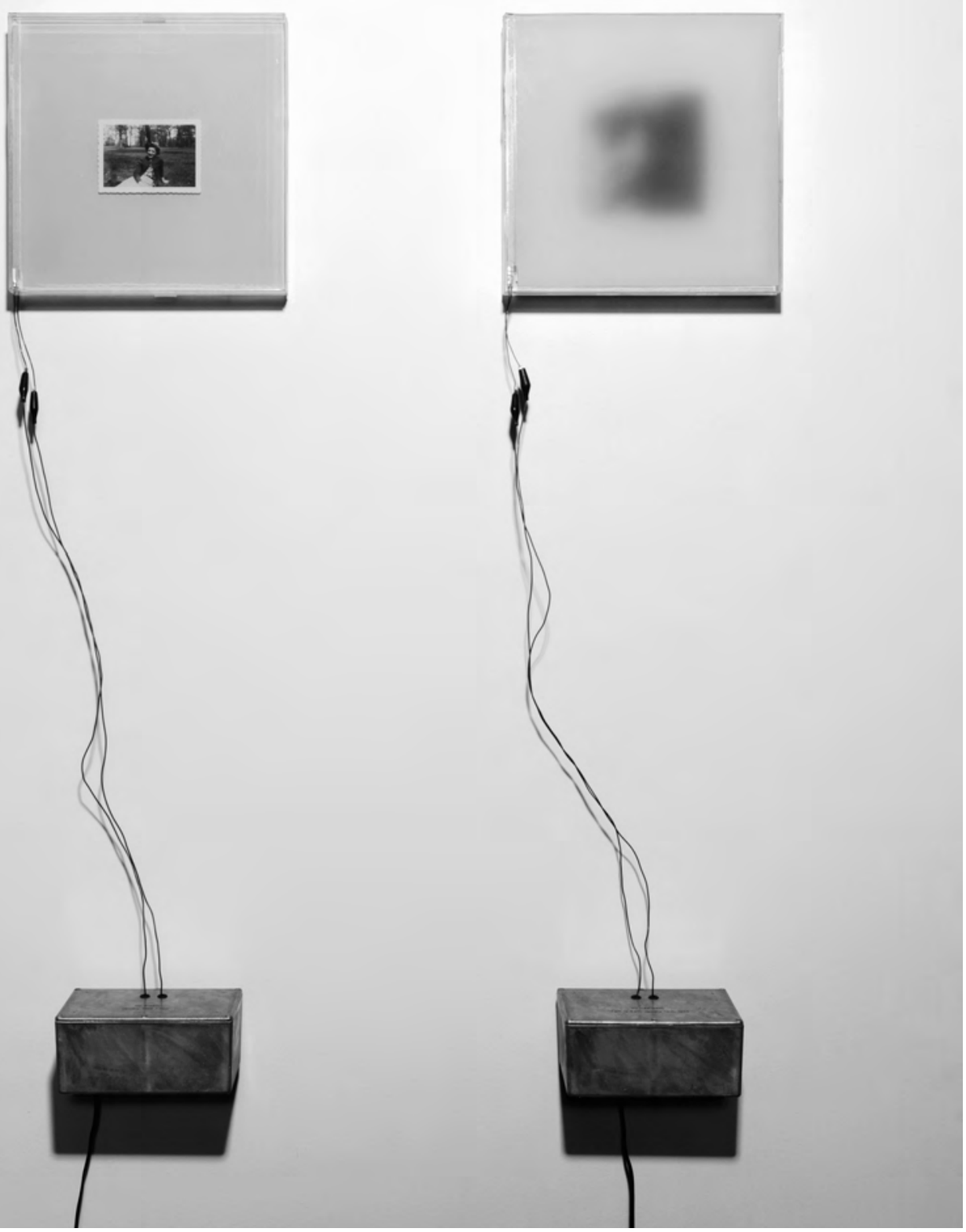

Abb. 1 Jim Campbell, Photo of My Mother und Portrait of My Father, 1994-96, aus der Memory Works Series 


\section{HAT DAS MEDIUM GEWICHT?}

In Jim Campbells Portrait of My Father (1994/95) und Photo of My Mother (I996) sind zwei Fotografien mit Apparaten verbunden, die Körperfunktionen des Künstlers aufgezeichnet haben (Herzschlag und Atemfrequenz). Diese Aufzeichnungen steuern die Sichtbarkeit der Fotos. (Abb. I) In Portrait of My Father bestimmt Campbells Herzschlag, der über einen Zeitraum von acht Stunden während des Schlafs aufgezeichnet wurde, die Frequenz, mit der die Fotos sichtbar und wieder unsichtbar werden. (Abb. 2) In ähnlicher Weise reguliert eine einstündige digitale Aufnahme von Campbells Atmung, wie sich die Glasscheibe vor dem Bild seiner Mutter beschlägt und wieder aufklart. (Abb.3) Die beiden Apparate, die den zeitlichen Verlauf dieser Effekte steuern, sind beschriftet und datiert («Mein Herzschlag von o bis 8 Uhr am I2. Januar I995» und «Mein Atem, Januar 1996, eine Stunde»). Es sind eindeutig alte Fotos, Beispiele für ein bereits obsoletes Medium, und sie stehen in Kontrast zu der raffinierten digitalen und elektronischen Technik der Installation. Aber sie erinnern auch in unheimlicher Weise an Siegfried Kracauers Analyse eines alten Fotos als flüchtiger Eindruck einer vergangenen Zeit ${ }^{1}$ und auch an Walter Benjamins «winzige[s] Fünkchen Zufall, [...] mit dem die Wirklichkeit den Bildcharakter gleichsam durchsengt hat $\gg^{2}$. Als Teil einer größeren Serie mit dem Titel Memory Works Series ${ }^{3}$ verweisen die beiden Fotos auf den Körper des Sohnes, auf dessen unbewusste und lebenserhaltende Bewegungen und Zeitlichkeiten. Als indexikalische Spuren, als Aufzeichnungen einer vergangenen Gegenwart der Eltern, produzieren sie eine Art technologisch vermitteltes ödipales Drama. Das Herz und der Atem bestimmen hier samt ihrer geradezu endlosen literarischen Metaphorizität das Erscheinen und Verschwinden einer flüchtigen Erinnerung. Die Fotos selbst scheinen zu leben und zu atmen, sie zittern in ihrer Opazität. Die Erinnerung ist, wie bei Proust, physisch unwillkürlich und kontingent, ihre Klarheit schwankt. Die Vergangenheit, obwohl verlockend nah, offenbart sich - ab und zu aufflackernd - stets als etwas, das sich unserem Zugriff entzieht, und das Versprechen der Fotografie erweist sich als hohl.
1 Vgl. Siegfried Kracauer, Die Photographie (1927), in: ders., Das Ornament der Masse, Frankfurt/M. (Suhrkamp) 1977, 21-39.

2 Walter Benjamin, Kleine Geschichte der Photographie (1931), in: ders., Das Kunstwerk im Zeitalter seiner technischen Reproduzierbarkeit. Drei Studien zur Kunstsoziologie, Frankfurt / M. (Suhrkamp) 1996, 45-64, 50.

3 Anm. d. Übers.: Hier weist die Autorin auf die Doppeldeutigkeit des Titels Memory Works hin, bei dem sich works als Verb oder Substantiv lesen lässt. 


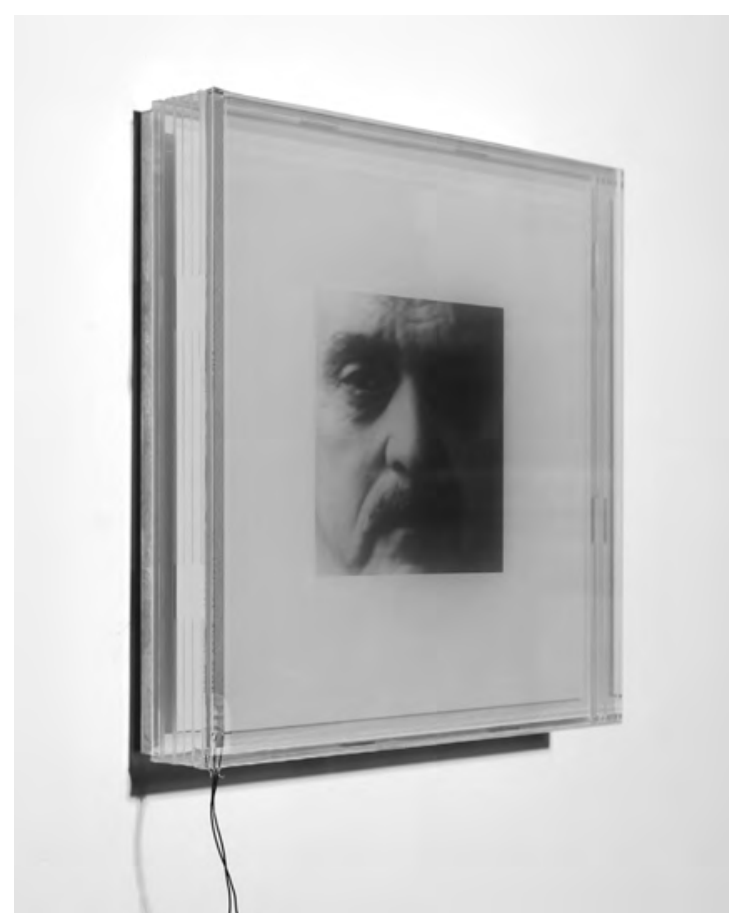

Abb. 2 Jim Campbell, Portrait of My Father, 1994-95, $180 \times 38 \times 15 \mathrm{~cm}$, elektronische Geräte, Glas, Fotografie, LCDMaterial
Geschlechterdifferenz durchzieht als Unterscheidung zwischen dem Analogen (der Kontinuität, dem Verbindenden, der Homogenität des Atems) und dem Digitalen (der Diskontinuität, dem binären An-Aus des Herzschlags) die Arbeiten. Die Mutter ist - selbstverständlich - aufseiten des Analogen, mit kontinuierlicher, wenngleich modifizierter Präsenz, der Atem besänftigend fließend, ohne Unterbrechung, ohne Mangel. Der Vater ist aufseiten des Digitalen, vergleichbar der An- und Abwesenheit des Herzschlags, dem Ursprung des Gegensatzes von Diastole und Systole, als gesetzgebende Kraft. Er nimmt eine steife, förmliche Pose ein; sein Gesicht ist nahe gerückt und füllt (ohne mise en scène) den Bildrahmen aus, Kamera und Betrachter gleichermaßen konfrontierend - das ist das Portrait of My Father. Die Mutter hingegen ist entspannt und strahlt Spontaneität aus, sie befindet sich auf dem Land, inmitten einer bukolischen mise en scène. Hier ist eine Zufälligkeit aufgerufen, wie sie der Amateurfotografie zugeschrieben wird, ohne dass die Aufnahme tatsächlich zufällig wäre - das ist das Photo of My Mother. Sichtbare Drähte verbinden die Aufzeichnungen der Körperfunktionen des Sohnes mit den Repräsentationen der Mutter und des Vaters. Diese wiederum sind durch das Stromnetz des Gebäudes unsichtbar miteinander verbunden: Die Kernfamilie, reproduziert für das Museum.

Portrait of My Father und Photo of My Mother, häufig zusammen gezeigt, sind dichte und anspielungsreiche Arbeiten. Worauf ich mich hier jedoch konzentrieren möchte, berührt diese Bedeutungsdichte scheinbar nur am Rande und zielt stärker auf die Frage ab, was diese Arbeiten eigentlich sind. Was ist hier das Medium? Die Fotografie? Digitale oder elektronische Medien? Ist das Konzept der <Installation> hinreichend? Ganz so, wie in Museen üblicherweise die Materialien eines Werks angegeben werden, waren die Arbeiten vor einiger Zeit in einer Ausstellung folgendermaßen beschriftet: «Speziell angefertigte Elektronik, Fotografie hinter Glas, LCD-Material». Die genaue Bezeichnung der eingesetzten Materialien wird zur vorrangigen Definition eines Mediums, sie ist ausschlaggebend für die Identität eines jeglichen im Museum präsentierten Kunstwerks. Und tatsächlich schwingt in unserem Alltagsverständnis des Medienbegriffs, egal ob beispielsweise bezogen auf Malerei, Bildhauerei, Musik oder Druckgrafik, der Aspekt der Materialität stark mit.

Das Konzept der Medienspezifität war für das Aufkommen der Filmwissenschaft historisch entscheidend. Seit dem Moment, als sich die Filmwissenschaft als Disziplin etablierte, am deutlichsten in den I97oer Jahren, gab es einen 
ständigen Druck, die Autonomie des Films gegenüber der Literatur, der bildenden Kunst und der Kommunikationsforschung zu erklären. Da weit voneinander entfernte Disziplinen das Vorrecht und die Autorität für sich beanspruchten, das Kino zu analysieren, schien es, dass der Film zu einem Gegenstand eigenen Rechts deklariert werden musste, dessen Einzigartigkeit und Andersartigkeit nach einer eigenen Methodologie verlangte. Fast sofort wurde jedoch deutlich, dass sich das Kino wegen seiner materiellen Heterogenität nicht als Medium im traditionellen Sinne begreifen ließ. Für Christian Metz manifestierte sich das in der Tatsache, dass das Kino mehrfach kodiert war. Für Peter Wollen aktivierte der Film alle Peirceschen Kategorien des Zeichens: Index, Ikon und Symbol. Und Jean-Louis Baudry sowie einer Reihe von Screen-Autoren der I 970er Jahre zufolge musste man sich das Kino als Apparat oder Dispositiv vorstellen, das unterschiedliche Elemente zusammenführt: den Bildschirm, den Projektor und den Zuschauer. ${ }^{4}$ Und doch: Trotz der Betonung der Heterogenität gehörte zum Verständnis des Films als Medium, um ihn abgrenzen und seine Eigenständigkeit als Studienobjekt begründen zu können, stets in irgendeiner Weise der Aspekt seiner Fundierung im Materiellen - sei es, dass die Medienspezifität historisch in der fotografischen Indexikalität (Bazin), in der Montage (Eisenstein) oder speziellen Filmtechniken wie dem Close-up (Balázs) angesiedelt wurde. ${ }^{5}$ Dieser Sinn des Mediums als Materie, als Materialität erreichte - möglicherweise - ihre Apotheose in einer von der Theorie inspirierten Filmpraxis der I97oer Jahre, dem strukturellen Experimentalfilm. Dessen Vertreter (Malcolm LeGrice, Peter Gidal, Paul Sharits etc.) setzten den Film mit seinen materiellen Bestandteilen gleich (Zelluloid, Körnung, Licht) und reduzierten damit die Dimension der Repräsentation so weitgehend, dass Gidal behaupten konnte, die Betonung der Materialität sei der Beweis für ein Bekenntnis zu einem marxistischen Materialismus. ${ }^{6}$

Das Konzept des ästhetischen Mediums wird häufig bis zu Lessing zurückverfolgt, der in seinem Laokoon ( I766) gegen die Vertreter der horazischen Doktrin des ut pictura poesis für das je <Eigene> der Malerei und der Dichtung stritt. Die Zeichen eines jeden Mediums müssen Lessing zufolge zu den Gegenständen passen, die sie bezeichnen, und schreiben somit die Relation zu Zeit und Raum vor. Da die Malerei mit Figuren und Farben operiert, die gleichzeitig nebeneinander bestehen, während die Dichtung ihre Elemente nacheinander anordnet, setzt Lessing die Malerei mit dem Raum (Simultaneität) und die Dichtung mit der Zeit (Sukzessivität) gleich. Die Materialität eines Mediums

Abb. 3 Jim Campbell, Photo of My Mother, $1996,180 \times 3^{8 \times 15} \mathrm{~cm}$, elektronische Geräte, Glas, Fotografie, LCD-Material

4 Vgl. Christian Metz, Language and Cinema, New York (Mouton De Gruyter) 1974; Peter Wollen, The Semiology of the Cinema, in: ders., Signs and Meaning in the Cinema, 3. Aufl., Bloomington, Ind. (Indiana Univ. Press) 1972, 79-106; JeanLouis Baudry, Ideological Effects of the Basic Cinematographic Apparatus (1970), in: Philip Rosen (Hg.), Narrative, Apparatus, Ideology. A Film Theory Reader, New York (Columbia Univ. Press) 1986, 286-298.

5 Vgl. André Bazin, Ontologie des photographischen Bildes (1945), in: ders., Was ist Film?, Berlin (Alexander) 2004, 33-42; Sergej Eisenstein, Dramaturgie der Film-Form. Der dialektische Zugang zur Film-Form (1929), in: Franz-Josef Albersmeier (Hg.), Texte zur Theorie des Films, 3. Aufl., Stuttgart (Reclam) 1998, 275-304; Béla Balázs, Theory of the Film. Character and Growth of a New Art, New York (Dover) 1970, insbes. Kap. 7.

6 Vgl. Peter Gidal, Materialist Film, London, New York (Routledge) 1989. 
7 Michael Fried, Foreword, in: Gotthold Ephraim Lessing, Laocoon. An Essay on the Limits of Painting and Poetry, Baltimore (Johns Hopkins Univ. Press) 1984 , xviii.

8 Clement Greenberg, Zu einem neueren Laokoon (1940), in: ders., Die Essenz der Moderne. Ausgewählte Essays und Kritiken, Amsterdam, Dresden (Verlag der Kunst) 1997, $56-81,58$.

9 Ebd., 69 .

10 Ebd., 70.

11 Ebd., 71.

12 Ebd., 72.

13 Ebd., 75.

14 Ebd., 76.

15 Ebd., 76. bestimmt sein Spektrum an Signifikationsmöglichkeiten, und jedes Medium ist daher durch eine Grenze gekennzeichnet, die gleichermaßen generativ wie beschränkend ist. Lessing verwendet die Metapher von Territorium und Grenze. Michael Fried hat Lessing als «Erfinder des modernen Konzepts des künstlerischen Mediums» ${ }^{7}$ bezeichnet. Die Doktrin des ut pictura poesis zielt dagegen auf eine Überschreitung dieser Beschränkungen oder Grenzen ab und gilt Lessing als gefährliches Durcheinander zwischen den verschiedenen Künsten. Die Konzeption des Mediums entsteht demnach im Angesicht einer Bedrohung. Und es ist die materielle Basis der Zeichen, die Gewicht hat und über die Möglichkeit einer unzweifelhaften Differenz und Identitätsgarantie entscheidet.

In der Kunstgeschichte wird am häufigsten Clement Greenberg aufgrund seiner notorischen Aufwertung der Flächigkeit der Avantgarde-Malerei mit der Gleichsetzung von Medium und Materialität in Zusammenhang gebracht. Es gibt bei ihm - wie bei Lessing - einen obsessiven Widerstand gegen die «Vermischung der Künste» ${ }^{8}$ und gegen den Verlust der Medienspezifität, der daraus resultiert. In Towards a Newer Laocoon (I940) entwirft Greenberg eine Geschichte, in der die Musik aufgrund ihrer Abstraktheit zum Inbegriff der Künste wurde, und «weil sie fast völlig in den physischen Eigenschaften ihres Mediums aufging» ${ }^{9}$. Nur wenn die anderen Künste lernen, sich nicht mit der Musik zu vermischen und nach deren Effekten zu streben, sondern stattdessen eigene Methoden erwerben, sich auf das zu beschränken, was über die ihnen zugeordneten Sinne verständlich ist, können sie die «Reinheit» ${ }^{10}$ und Selbstgenügsamkeit der Musik erlangen. Reinheit liegt für Greenberg in der «Akzeptanz der Beschränkungen des Mediums»"11, denn, «um die Identität einer Kunst wiederherzustellen, muß die Opazität ihres Mediums betont werden ${ }^{12}$. Greenberg zufolge ist das Medium mit seiner Materialität gleichzusetzen, und dessen Gewicht definiert sich in allererster Linie über seine Widerständigkeit. Dies ist der Widerstand des Realen. Es setzt eine äußerste Grenze, eine, die zwangsläufig respektiert werden muss, denn ihre Überschreitung ist undenkbar. Die Geschichte der Avantgarde ist deshalb für Greenberg «die Geschichte ihrer schrittweisen Anerkennung der Widerständigkeit ihres Mediums» ${ }^{13}$. Die Grenze der Malerei sei die flache Leinwand - ein Gesichtspunkt, der von perspektivisch realistischen Gemälden, die bemüht sind, die Illusion des dreidimensionalen Raums zu erzeugen, verkannt würden. Greenberg spricht von der «einen realen, materiellen Ebene der wirklichen Leinwandfläche» ${ }^{14}$ (im Gegensatz zu den fiktiven Ebenen der Bildtiefe). In einem bemerkenswerten Abschnitt schreibt er:

Wo der Maler noch versucht, reale Gegenstände anzudeuten, werden ihre Formen flach und breiten sich in der dichten zweidimensionalen Atmosphäre aus. Eine vibrierende Spannung entsteht, wenn die Gegenstände versuchen, ihr Volumen gegen die Tendenz der realen Bildfläche zu behaupten, ihre eigene materielle Flächigkeit durchzusetzen und die Gegenstände zu Silhouetten zusammenzupressen. In der nächsten Phase zerbricht und zersplittert der realistische Raum in lauter einzelne Flächen, die parallel zur Bildoberfläche nach vorne kommen. ${ }^{\mathbf{1 5}}$ 
Dieser realistische Raum verschwindet für Greenberg nicht einfach, sondern er wird «zusammengepresst», wird «flach», er «zerbricht» und «zersplittert». In dieser Rückkehr zum Realen, zur Materie, zur «wirklichen» Oberfläche des Bildes liegt eine gewisse Gewalt. Von der Renaissance bis zum «erste[n] wirkliche[n] Avantgarde-Maler $>^{16}$, Courbet, hatte die Malerei das Reale im Inneren des Bildes, in seiner Tiefe angesiedelt. Doch es ist nicht die mimetische oder illusionistische Darstellung von Objekten und Personen, die für Greenberg auf dem Spiel steht, vielmehr ist es die Positionierung des realen Raums. Es überrascht nicht, dass es in dieser kunstgeschichtlichen Betrachtungsweise die Perspektive ist, die mit Geringschätzung behandelt wird und überwunden werden sollte. In Greenbergs Darstellung verlegt die Avantgarde-Malerei den Ort des Realen vom illusorischen dreidimensionalen Raum weg hin zum eigentlichen Materiellen in all seiner Opazität. In gewisser Weise stellt dies eine Transformation vom Realismus zum Realen dar.

Anders als ihm üblicherweise nachgesagt wird, betrachtete Greenberg diese Obsession mit der Flächigkeit der Leinwand nicht als Essenz und ahistorische Natur der Malerei, als ihre Ontologie oder einzige wahre Berufung. Vielmehr behauptet er, dass es keine Essenz abstrakter Kunst gebe, die zwingend auf der planen Oberfläche der Leinwand festgehalten werden müsste, und dass diese Situation grundlegend historisch sei, sich der Beharrlichkeit dieser Zeit verdankt. Wie lautet der historische Imperativ, der das Reale vom perspektivischen Raum auf die plane Bildoberfläche verlegt? Ein Illusionismusverdacht, den auch andere modernistische Medien teilen? Skepsis hinsichtlich des Zugangs zur Welt? Ich stelle diese Frage für den Moment zurück, insbesondere weil es mein Ziel ist, eine Geschichte des Denkens über das Medium und schlussendlich den Platz des Films in dieser Geschichte zu analysieren.

Das Interesse am Konzept des Mediums erlebte eine zweite Konjunktur (und vielleicht eine dritte) in der Begegnung mit der Fotografie, dem Film und den digitalen Medien. In den Texten von Stanley Cavell, Rosalind Krauss und David Rodowick werden Fotografie und Film von zentraler Bedeutung für die Diskussion über das Schicksal des Mediums. In einer Zeit, die immer häufiger als «postmedial» etikettiert wird und in der die Postmoderne und der kulturelle Traum von digitaler Immaterialität die Begriffe des Materiellen, der Materialität und des Realen bedrohen oder destabilisieren, ist die Frage nach dem Medium einmal mehr drängend. Für Cavell, Krauss und Rodowick ist, um ein Medium zu definieren, die materielle, physische Basis und Untermauerung notwendig, aber nicht hinreichend. Aber für alle drei spielen die Fotografie und der Film eine entscheidende konzeptionelle Rolle. Im Grunde genommen ist es so, als wäre das fotografische Bild der Inbegriff der Idee eines Mediums. Während sich für Cavell kein Medium über seine physische, materielle Basis definieren lässt, ist es das Konzept des Automatismus - das nicht gleichbedeutend, aber eng verwandt mit der automatischen Aufzeichnung der Welt durch die Fotografie ist -, welches ein Medium spezifiziert und dessen Möglichkeiten 
17 Vgl. Stanley Cavell, The World Viewed. Reflections on the Ontology of Film, erw. Ausg., Cambridge, Mass. (Harvard Univ. Press) 1979, insbes. Kapitel 14.

18 Ebd., 105.

19 Vgl. David Norman Rodowick, The Virtual Life of Film, Cambridge, Mass. (Harvard Univ. Press) 2007, 19.

20 Vgl. Rosalind Krauss, Reinventing the Medium, in: Critical Inquiry, 2/25, Winter 1999, 290-297.

21 Zur Entstehung der Konzeption des Mediums als «von sich selbst differierend» vgl. Rosalind Krauss, "A Voyage on the North Sean: Broodthaers, das Postmediale, Zürich, Berlin (diaphanes) 2008, 69 . generiert. ${ }^{17}$ Die materielle Basis des Mediums Film besteht gemäß seiner bekannten Definition aus «Abfolgen automatischer Weltprojektionen» ${ }^{18}$. Die Leinwand fungiert sowohl als Zugang zur wie auch als Abgrenzung gegen die Welt. Die Bedeutung des Films liegt für Cavell darin, dass er so vollständig und erfolgreich eine Form moderner Entfremdung des Subjekts von der Welt verkörpert, einen Skeptizismus gegenüber der Möglichkeit der Welterkenntnis. In dialektischer Weise aktiviert er sowohl das Verlangen nach dieser Erkenntnis (als hoffnungsvoller Anreiz) und die Anerkennung der spezifischen Art, in der die Welt nun unvermeidlich von uns entfernt ist. Das fotografische Bild ist als indexikalisches Zeichen (als automatisches Zeichen in seiner Terminologie) von grundlegender Bedeutung für diese Rolle. Rodowick, der sich stark an Cavell anlehnt, betrachtet den Film als exemplarisches Medium, insofern er in seiner Heterogenität die unvermeidliche Heterogenität eines jeden Mediums zum Vorschein bringt. ${ }^{19}$ Für Krauss bedeutet die Fotografie, die ihr als von vornherein heterogen und entschieden nicht-autonom gilt, sowohl die eigentliche Zerstörung des Konzepts des Mediums (durch ihre Vernichtung der Aura) als auch das Mittel zu seiner Neuerfindung im Moment seines Obsolet-Werdens (im Werk von solchen Künstlern wie James Coleman).$^{20}$ In vergleichbarer Weise provoziere der Film eine neue Konzeption des Mediums als in sich selbst differenziert, als «von sich selbst differierend.» ${ }^{21}$

Der Film und die Fotografie werfen folglich beide sehr dringlich die Frage nach dem Gewicht des Mediums auf und besetzen einen entscheidenden (und mit der Auffassung vom Film als «dem letzten Medium» oder von der Fotografie, die den Niedergang des künstlerischen Mediums einleitete, vielleicht fatalen) Platz in seiner Rezeptionsgeschichte. Teilweise hat dies sicherlich mit der Indexikalität des fotografischen Bildes zu tun, die ihm eine besondere - sei es positive oder negative - Verbundenheit mit dem «Außen», der Welt, dem Realen erlaubt: Cavells Betonung automatisch aufgenommener Bildfolgen; Rodowicks Verbindung der Fotografie und des Films mit der indexikalischen Einschreibung von Zeit und Geschichtlichkeit und sein an Cavell erinnerndes Insistieren auf der ethischen Verpflichtung des Mediums Film, uns wieder mit der Welt zu verbinden; sogar Krauss' Auffassung, dass der indexikalische Status der Fotografie ihre Autonomie vereitele, indem er die Ambiguität des Realen einsickern lässt. Wenn Greenberg in der modernen Malerei eine Verschiebung des Realen von den Tiefen des perspektivischen Raums auf die Oberfläche der Leinwand feststellt, ist es ebenso möglich, eine weitere Verschiebung des Realen von der Oberfläche des Gemäldes, von den Rohmaterialien der Farbe selbst, zur indexikalischen Spur von Fotografie und Film nachzuzeichnen. Und angesichts des Veraltens von chemischen Verfahren in Fotografie und Film stellt sich unausweichlich die Frage: Was kommt als Nächstes?

Doch bevor ich in dieses Dickicht eindringe, würde ich gerne eine Weile im Bereich der chemischen Fotografie verweilen. Innerhalb der Medienwissenschaften scheinen die digitalen Medien für die Medienspezifik von Film und 
Fotografie eine Bedrohung darzustellen, aber nur, wenn Film und Fotografie als notwendigerweise chemisch basiert wahrgenommen werden - daher die Wiederkehr der Indexikalität als wichtiger theoretischer Bezugspunkt. Doch das Konzept der Indexikalität selbst garantiert sehr wenig, bloß die Versicherung einer Existenz, nicht den gesamten Realismus der perspektivischen Repräsentation. Am Beispiel des Abdrucks auf dem Grabtuch von Turin hat Georges Didi-Huberman Indexikalität als dann am wirkungsvollsten analysiert, wenn ihr Ikonizität, Erkennbarkeit fehlt - «[d]ie Gestaltlosigkeit hat [...] den Wert eines Existenz-Beweises».22 Gerade die bezeichnende Opazität bestätigt die vergangene Präsenz des Objekts.

Die Frage der Indexikalität ist somit zwingend eine Frage von Geschichte und Geschichtlichkeit, aber die Lesbarkeit dieser Geschichte, ihre Bedeutsamkeit, steht zugleich immer in Zweifel. Didi-Hubermans jüngster Beitrag zu dieser Debatte war eine Analyse von vier Fotografien, die vom Sonderkommando in Auschwitz aufgenommen und in einer Tube Zahnpasta versteckt aus dem Lager hinaus nach Polen geschmuggelt wurden. ${ }^{23}$ In einer Polemik zur Sagbarkeit, zur Darstellbarkeit des Holocaust, aber auch zur Referentialität des fotografischen Bildes argumentiert Didi-Huberman, dass es einen Punkt der Berührung zwischen jenen Bildern und dem Realen gebe. Um sich von Claude Lanzman sowie von dem ähnlich sich äußernden Gérard Wajcman abzusetzen, der behauptet hat, «es gibt kein Bild von der Shoah» und «nicht alles Reale lässt sich im Bild festhalten», betitelt Didi-Huberman sein Buch Images Malgré Tout (Bilder trotz allem) - wobei das «trotz» nicht nur auf die Umstände anspielt, unter denen die Bilder aufgenommen wurden, sondern auch auf «die zwingende Notwendigkeit und die unvermeidliche Lückenhaftigkeit des Bildes». ${ }^{24}$ In seinen Analysen der Fotografien betont er nicht deren grausamen Inhalt (die schrecklichen Bilder von brennenden Leichen und von Frauen, die wie Schafe in die Gaskammer getrieben werden), sondern die den Bildern eingeschriebenen Spuren des Aufnahmeaktes, den Prozess ihrer Entstehung: Das Schwarz in der Bildecke zeugt von der Notwendigkeit, dass sich der Fotograf versteckt halten musste (ironischerweise in einer leeren Gaskammer); die mangelhafte Schärfe belegt das Tempo, die Eile, zu der die nur wenigen Augenblicke zwangen, die für die Aufnahmen zur Verfügung standen; der schiefe Bildrahmen verweist auf die Notwendigkeit, die Kamera zu verbergen und die daraus folgende Unmöglichkeit, den Sucher zu benutzen - was auch die fast völlige Abstraktion des letzten Bildes zu erklären hilft. Es sind die nicht-ikonischen, nicht-mimetischen Aspekte der Bilder, die die Spuren des Realen tragen. Das Indexikalische ist in diesem Fall ein Hinweis auf das Risiko und die Schwierigkeiten, die das Fotografieren bereitete, sowie auf die Art und Weise, wie die Repräsentation selbst die Kennzeichen der Beschränkungen des Apparats in sich trägt. Doch die Fotografien selbst können das nicht zum Ausdruck bringen, vielmehr müssen sie in einen größeren diskursiven Zusammenhang von Briefen und Erinnerungen gestellt werden, was Didi-Huberman später als Montage bezeichnet.
22 Georges Didi-Huberman, Anhaltspunkt für eine abwesende Wunde. Monographie eines Flecks, in: Bettine Menke, Barbara Vinken (Hg.), Stigmata. Poetiken der Körperinschrift, München (Fink) 2004, 319-340, 324.

23 Vgl. Georges Didi-Huberman, Bilder trotz allem, München (Fink) 2007.

24 Ebd., 73. 
Mich interessiert hier jedoch vor allem, dass in dieser Analyse die Geschichtlichkeit der Fotografie, ihr Zugang zum Realen, mit Risiko, Gewalt und Tod verknüpft ist, dem Extrempunkt des Realen, sie ist widerständig, ohne zu appellieren. In «Mort tous les après-midi» («Death Every Afternoon»), seinem kurzen Aufsatz über den Stierkampf, hat André Bazin ebenfalls den zwingendsten Beweis für den filmischen Zugang zum Realen in der Gefahr und dem Todespotenzial ausgemacht. ${ }^{25}$ Tod im Film war für ihn etwas Skandalöses, eine Obszönität, die Wiederholung eines Vorgangs, der doch die Apotheose des Einzigartigen sei. Und er war so nur im Kino realisierbar, das den Übergang vom Leben zum Tod aufnehmen und unendliche Male wiedergeben kann. Aber Gefahr, Lebensgefahr ist auch als die Situation desjenigen sichtbar, der in DidiHubermans Szenario die Kamera hält. Der unbekannte Fotograf von Auschwitz setzte sein Leben aufs Spiel, um die grauenhaften Geschehnisse im Todeslager festzuhalten. Die Gewalt, die für Greenberg darin liegt, dass illusionistische Raumtiefen an der realen Oberfläche des Gemäldes aufeinanderkrachen, findet sich nun am realen Ort der Produktion des Bildes wieder. Nicht so sehr die realistischen oder repräsentativen Eigenschaften des Bildes sind es, um die es hier geht, sondern das Ereignis seiner Entstehung. Die Fotoserie wird zum Ereignis ihrer eigenen Produktion.

Michel Serres' Nachdenken über die Sinne in seinem Buch Die fünf Sinne beginnt mit und greift immer wieder zurück auf eine ausgesprochen detailreiche Beschreibung eines Schiffbrandes, in der Serres schildert, wie er von Angst gepeinigt versucht, seinen Körper durch ein kleines Bullauge zu zwängen, um zu fliehen. ${ }^{26}$ Wiederum ist es die Gefahr, genauer gesagt die Todesgefahr, die auch Serres veranlasst, über den Körper als Medium zu schreiben und sich des Körpers mit seinen Beschränkungen und Fähigkeiten in der Bewältigung des Raums schlagartig bewusst zu werden. Wie in Henri Lefebvres Analyse der Produktion von Raum ${ }^{27}$ ist es der Körper, der für die Orientierung in der Welt entscheidend ist, und für Serres ist er auch entscheidend am Entstehen einer Gewissheit über das Ego, das Ich, beteiligt.

$25 \mathrm{Vgl}$. André Bazin, Death Every Afternoon, in: Ivone Margulies (Hg.), Rites of Realism. Essays on Corporeal Cinema, Durham, NC (Duke Univ. Press) 2002, 27-31.

26 Vgl. Michel Serres, Die fünf Sinne. Eine Philosophie der Gemenge und Gemische, Frankfurt/M. (Suhrkamp) 1993.

27 Vgl. Henri Lefebvre, The Production of Space, Cambridge, Mass. (Blackwell) 1991.

28 Serres, Die fünf Sinne, 14.
Ich war drinnen, ich war draußen.

Wer, ich?

Jeder begreift das, und dazu bedarf es nicht einmal einer dramatischen Situation oder einer Katastrophe. Es genügt, durch eine kleine Öffnung, einen sehr engen Durchgang hindurchzumüssen oder in schwindelnder Höhe auf eine Rampe, einen Vorsprung zu treten, damit der Körper Alarm schlägt. Der Körper versteht es ganz von sich aus, «ich» zu sagen. Er weiß, wie weit ich jenseits der Reling bin; er weiß, wann ich draußen bin. Er mißt die Abweichung vom Gleichgewicht, greift unverzüglich regulierend ein, weiß genau, wann wir uns zu weit vorgewagt haben. Die Zönästhesie versteht es ganz von sich aus, «ich» zu sagen. Sie weiß, daß ich drinnen bin; sie weiß, daß ich freikomme. Der innere Sinn schreit das «ich» heraus, er ruft es, und manchmal brüllt er es. Von allen Dingen in der Welt nimmt der gemeine Sinn noch am ehesten Anteil am Körper. ${ }^{28}$ 
Dieses Wissen des Körpers und somit auch des Ichs basiert im Ursprung auf dem Tastsinn - auf einer Berührung, einem Kontakt, der dem Widerstand der Materie begegnet. Die Haut wird zum ersten Medium (was Serres zu einer langen Abhandlung über die Beziehung der Frau zur Kosmetik und deren Beziehung zu den Sinnen veranlasst). Die Beziehung eines Malers zur Leinwand wie auch die des Schriftstellers zum Blatt Papier hat zuerst und vor allem anderen mit Berühren zu tun, mit Drucken, Abdrucken, Aufdrucken.

\begin{abstract}
Bevor irgendeine Form entstehen, eine Farbe oder ein Ton aufgetragen werden kann, muß man den Träger berühren. Die Haut, den Überzug, die Hülle, die Leinwand. Das Bild entsteht auf einer entfalteten Mannigfaltigkeit, die Karte wird auf ein Blatt gezeichnet oder gedruckt ... Am Anfang steht der Tastsinn, am Anfang steht der Träger ... Das Auge, das stets auf Distanz bleibt, liegt auf der faulen Haut, bleibt gänzlich passiv. Kein Impressionismus ohne imprimierende Kraft, ohne die Pressionen des Tastsinns. ${ }^{29}$
\end{abstract}

Dass der Tastsinn derart insistent ist und dass man in ihm die Grundlage für das Konzept eines <Mediums〉 sieht, liegt Serres zufolge nicht im künstlerischen Schaffensprozess begründet, sondern beides folgt aus der nackten Angst eines existenziell gefährdeten Körpers, der gegen die Festigkeit der Materie ankämpft, um sich aus einer Gefahr zu befreien. Gefahr ist der Berührungspunkt mit dem Realen - für Serres wie für Bazin und Didi-Huberman.

Wichtig ist festzustellen, dass die besondere Nähe zur Gefahr und zur Darstellung des Todes, die Bazin für das Kino feststellt, nicht mehr nur vom Kino allein behauptet werden kann. Weil Fernsehen, Video und digitale Medien zeitbasiert sind und man mit ihnen sowohl produzieren und senden als auch empfangen kann - kurz, aufgrund ihrer 〈liveness> -, sind sie alle in der Lage, den einzigartigen Tod zu repräsentieren und dies unendlich oft zu wiederholen.

Der Umstand, dass von den Protestaktionen bei den letzten Wahlen im Iran auf YouTube kurze Videos verbreitet wurden, auf denen die Erschießung von Oppositionellen zu sehen ist, bezeugt diese Faszination. Viele Reaktionen darauf bestätigen, dass die Darstellung des Todes immer noch als so skandalös oder obszön wahrgenommen wird, wie Bazin behauptet hat. Ich komme gleich auf die Frage des Verlusts der vermeintlichen Medienspezifität zurück, wie sie in Bezug auf ein Konzept des Realen definiert wurde. Wenn die Darstellung des Todes als eine äußerste (ethische, moralische und ästhetische) Grenze zwingend ist, dann kann sie nicht länger Medienspezifität garantieren. Medienspezifität ist, wie selbst Greenberg schon wusste, historisch und veränderlich.

Dennoch hat das Konzept des Mediums immer schon mit Grenzen zu tun gehabt und ist ohne sie sogar undenkbar. Der Untertitel von Lessings Laokoon lautet: Über die Grenzen der Malerei und Poesie. Greenberg zufolge kämpft in der Bildhauerei der Marmor, um der Form, die der Künstler ihm aufzuzwängen versucht, Widerstand zu leisten, und die plane Oberfläche führt Krieg gegen die Zumutung von Ebenen in der Tiefe des Bildes. Und nach Cavells Ansicht 
ist es der Film, der seine eigenen Grenzen anerkennen muss: «außerhalb der Welt zu sein, und ich außerhalb des Films» ${ }^{30}$. Die Grenze mag als absolute existieren (wie bei Lessing) oder als Herausforderung, der es sich zu stellen gilt, die überwunden oder bekämpft werden muss (wie bei Rodowick, demzufolge der Film die ethische Verpflichtung hat, das Subjekt wieder mit der Welt zu verbinden). Aber um eine Grenze handelt es sich in jedem Fall - eine, die dem betreffenden Medium Identität und Spezifität verleiht, eine, die durch Verzicht auf ein 〈Jenseits> sozusagen ein geschütztes Gebiet absteckt und umgrenzt. Im Werk von Michael Fried findet der Begriff der Grenze seine vielleicht verblüffendste und kraftvollste Ausprägung. Sein Aufsatz «Kunst und Objekthaftigkeit» (1967, deutsch 1995) wendet sich gegen das, was er als die «Theatralität» der «literalistischen Kunst» (Minimalismus, Primary Structures, Specific Objects) bezeichnet, und gegen die daraus resultierende Fusion der einzelnen Künste wie auch gegen die Erklärung des Endes der Künste und gegen die Auffassung, dass «die Künste nun endlich auf eine immens wünschenswerte, implosive, endgültige Synthese zugleiten. Tatsächlich aber haben sich die einzelnen Künste niemals so explizit wie heute mit den Konventionen beschäftigt, die ihre jeweilige Essenz ausmachen. [...] Die Konzepte der Qualität und des Wertes - und insoweit diese für die Kunst von zentraler Wichtigkeit sind, auch das Konzept der Kunst selbst - baben eine Bedeutung, oder haben ibre volle Bedeutung nur innerbalb der einzelnen Künste. Was zwischen den Künsten liegt, ist Theater». ${ }^{31}$ Fried bezieht sich hier auf Werke von Künstlern wie Donald Judd, Tony Smith and Robert Morris, die die Grenzen des für sich stehenden Kunstobjekts überwinden und den Zuschauer zum entscheidenden Bestandteil der Wahrnehmung des Werks erklären. Medienspezifität wird von Fried als Verteidigung gegen eine Unbegrenztheit heraufbeschworen, die die eigentliche Idee von Kunst gefährde. Dieselbe Angst vor dem Ende des Ästhetischen, vor dessen Vernichtung durch eine promiske Mischung der Medien und vor einem Verlust der Unterschiede findet sich bei Rosalind Krauss, die in ihren Schriften zwar ganz andere Schwerpunkte setzt, aber ebenfalls für den Erhalt des Konzepts des Mediums eintritt. Für sie besteht die beständige Gefahr in der Kommodifizierung der Kunst. Stark beeinflusst von Walter Benjamin sieht sie die Kunst von einem Prozess betroffen, durch den die Objekte Einzigartigkeit und Unterscheidbarkeit zugunsten von Gleichwertigkeit und Austauschbarkeit verlieren. Das Medium ist bei Krauss der Ansatzpunkt des Widerstands gegen die Verwischung der Spezifität von Kunstgattungen zugunsten der Idee von Kunst im Allgemeinen - die ihrer Meinung nach beispielsweise in der globalen Modeerscheinung intermedialer Kunst oder von Installationen erkennbar ist. ${ }^{32}$

30 Cavell, The World Viewed, 146. 31 Michael Fried, Kunst und Objekthaftigkeit (1967), in: Gregor Stemmrich (Hg.), Minimal Art. Eine kritische Retrospektive, Dresden, Basel (Verlag der Kunst) 1995, 334-374, 361 (Herv. i. Orig.).

32 Vgl. Krauss, "Voyage», Kap. 6.
Wenngleich die Verfechter und Verteidiger des Konzepts des Mediums verschiedene ideologische Tendenzen vertreten, halten sie doch alle auf ihre Weise die Vorstellung der Fundierung des Mediums im Material oder in der Materialität aufrecht und als logische Folge daraus auch die der Grenze. Lessings Furcht vor einer Vermischung der Künste findet in Greenbergs Festhalten an 
der Medienspezifität ihren Widerhall, ebenso in Frieds Skepsis gegenüber der unbestimmten Ausdehnung des Werks, in Cavells medienspezifischen Automatismen und in Krauss' Angst vor der Gleichwertigkeit und dem Verlust der Differenzierung. Das Ästhetische scheint nur möglich, wenn die Grenze denkbar ist. Wenngleich die digitalen Medien in der Wiederbelebung des Konzepts des Mediums eindeutig eingeschlossen sind - und dabei wegen ihrer Immaterialität eine Bedrohung darstellen, der das Medium durch Festhalten an der Materialität und unerbittlichen Widerständigkeit des Materiellen begegnet -, waren bereits Fotografie und Film die Vorboten einer gefährlichen Heterogenität und Instabilität. Bazins und Didi-Hubermans Betonung der Gefahr und des Todes ist in der Hinsicht bezeichnend. Momente der Gefahr kennzeichnen in Film und Fotografie die potenziell extremste Überschreitung von Grenzen, wo das Reale die Grenze, durch welche es vom Medium getrennt ist, zu überwinden droht.

Jim Campbells Portrait of My Father und Photo of My Mother verleihen der Fotografie eine zentrale Rolle, aber nur durch das Nebeneinanderstellen oder das Aufeinanderprallen mit einem anderen Aufzeichnungsmodus, einem, der vormals nicht als ästhetisch, sondern vielleicht eher als medizinisch betrachtet wurde: mit den Aufnahmen des Atems und des Herzschlags. Die zeitliche Dimension des Werks entspricht der des Körpers, oder vielleicht kann man sagen, der Körper wird eine Art Medium (in ganz anderem Sinne allerdings als bei der Künstlerin Orlan). In dieser Hinsicht wird das Werk Zeuge (und Beteiligter) des Ausblutens des Ästhetischen, seines Übergangs zu einem x-beliebigen Material.

Diese Krise des Ästhetischen ist bereits von Frederic Jameson festgestellt worden, der behauptet, jegliche Vorstellung vom Bild als Kunst sei von der Logik der Kommodifizierung assimiliert worden, und alles im täglichen Leben sei inzwischen ästhetisiert - womit diese Vorstellung in der «Zeit des Weltbildes» ${ }^{33}$ keine Überzeugungskraft mehr habe. Das Alltagsleben ist mit Bildern gesättigt, mit Leinwänden und Tonaufnahmen. Während die Rückkehr der Theorie zum Medium zweifellos bei dessen Zugriff auf das Reale ansetzt - das Reale als Entgegnung auf die pervasive baudrillardsche Simulation, die sowohl mit der Postmoderne als auch dem Digitalen in Verbindung steht -, ist sie auch eine Antwort auf eine Art Ausfließen, Ausbluten oder Leck, das gerade auch dem Konzept der Grenze Gewalt anzutun scheint. Judd und Morris sprachen von der Erschöpfung der rechteckigen Bildfläche in der Malerei. Man hatte in ihrem Rahmen nur begrenzte Gestaltungsmöglichkeiten, daher war für sie die Erweiterung des Werkbegriffs, die Einbeziehung des realen Raums, von zentraler Bedeutung. Auch die Kinoleinwand ist ein Rechteck - eines, bei dem die Kantenlängen seit Jahrzehnten in erstaunlich standardisiertem Verhältnis zueinander stehen. Aber anders als in der Museumskultur lautet in der Screen Culture die Antwort auf diese Beschränkung nicht, das Kunstwerk anders zu rahmen, den Rahmen auszudehnen oder zu überwinden oder seine Objekte neu
33 Vgl. Fredric Jameson, Transformations of the Image in Postmodernity, in: ders., The Cultural Turn. Selected Writings on the Postmodern, $1983^{-1998, ~ N e w ~ Y o r k ~(V e r s o) ~} 1998$, 99-113. 
34 Vgl. Erwin Panofsky, Die Perspektive als "symbolische Form" (1927), in: ders., Aufsätze zu Grundfragen der Kunstwissenschaft, Berlin (Volker Spiess) 1980, 99-167. zu verhandeln, sondern die Leinwand vom Vorführraum zu entkoppeln und nach überallhin zu verfrachten. Folglich haben wir es hier nicht mit der Erschöpfung des Rechtecks zu tun, sondern mit dessen Transport: die Videofenster, Bildanzeigen, Displays und dergleichen von YouTube, Mobiltelefonen, von Fernsehen und Computer und sogar die gigantischen Projektionsflächen an den Wänden der Gebäude in Tokio, Hong Kong oder New York künden davon. Die Angst, die der Mediensaturierung anhaftet, deutet auf einen kritischen Neuansatz des Konzepts der Unendlichkeit, demzufolge sich alles unendlich oft reproduzieren lässt (etwa auf Screens aller Art) und - in Frieds Terminologie $-\ll$ nie-endend» ist. Panofsky interpretierte die perspektivische Darstellung in der Renaissance als Symptom und Ausdruck eines neuen Konzepts, dem der Unendlichkeit, die sich im Fluchtpunkt manifestiert. ${ }^{34}$ Doch handelte es sich dabei um eine Unendlichkeit der Repräsentation, die das menschliche Subjekt bestätigte und bestärkte sowie Theokratie durch Anthropokratie ersetzte. Im Zeitalter der Verbreitung von Bildflächen aller Art ist das Konzept der Unendlichkeit von neuer Qualität: Es existiert nicht mehr in der Tiefendimension des Bildes, sondern in dessen Expansion, seiner scheinbar endlosen Extension und Multiplikation, seiner Besetzung fast jeglichen Orts. Diese Art der Unendlichkeit der Repräsentation - weit davon entfernt, bestätigend zu wirken - provoziert die Angst davor, dass das Konzept des Mediums aufweicht, welches in demjenigen der Grenze und somit dem Endlichen und der Widerständigkeit des Materials verankert ist.

Und dennoch: Campbells Puls und Atemfrequenz sind nicht irgendein beliebiges Material. Es sind Spuren eines Körpers, der fühlt und wahrnimmt. Für Greenberg ist das Medium der Berührungspunkt mit dem Realen, dem Physischen, demjenigen also, was die Kunst sinnlich macht, das heißt ästhetisch. Eine andere Lesart von Campbells Werk würde es als Beleg dafür nehmen, dass der Körper das Medium par excellence ist, das in der Entzifferung der Fotografie als Spur der Zeit immer schon inbegriffen ist - der Körper, der da ist und nicht da ist, im Bild. Denn der Körper des Betrachters von Campbells Arbeit ist zwangsläufig in deren zeitliche Dimension einbezogen (welche gleichzeitig die Zeitdimension des Körpers des Künstlers ist), insofern das Erscheinen und Verschwinden beziehungsweise das abwechselnde Verschwimmen und Klarwerden des Bildes den Betrachter zwingen, sich anzustrengen, um zu erkennen. Und in dieser Anstrengung gelangt der Betrachter wiederum zur Erkenntnis der Arbeit und der unhintergehbaren Präsenz des Körpers.

(Aus dem Englischen übersetzt von Victoria Piel) 